\title{
5. An exploration of the concept of design in information systems
}

\author{
JUDY MCKAY \\ SWINBURNE UNIVERSITY OF TECHNOLOGY
}

\author{
PETER MARSHALL \\ UNIVERSITY OF TASMANIA
}

\author{
GREG HEATH \\ SWINBURNE UNIVERSITY OF TECHNOLOGY
}

\section{Abstract}

This chapter explores the concepts of design and design science in a number of disciplines, including information systems (IS). The authors identify and explore various viewpoints or perspectives on design in a number of disciplines including management, engineering, architecture and product development. These perspectives include design as product, design as process or action, design as intention, design as planning including modelling, representation and method, design as communication, design as user experience, design as a value, design as professional practice and design as service. This broad and diverse set of perspectives is contrasted with what is identified and characterised by the authors as a limiting technological perspective of design adopted by the current extant papers in the mainstream IS journals. The chapter concludes with a call to broaden and further develop the concept of design, and hence design science, into an integrated holistic socio-technical view that includes the human social and organisational factors alongside the technical factors. 


\section{Introduction}

There has been rapid growth in interest in the notion of design - and hence in the building of a design science - in information systems (IS) in the past decade. Many seminal papers have been published that have proved very influential in the field, and thus have inevitably begun to shape the discourses that take place (essentially through publications) and the practices around design science that emerge over time. Notable among these seminal papers is that of Hevner et al. (2004) entitled 'Design science in information systems research', published in MIS Quarterly. It needs to be acknowledged, however, that this work was itself informed by some work of earlier writers, particularly Walls et al. (1992), March and Smith (1995) and Markus et al. (2002).

While the position of these authors and others has formed, to an extent at least, somewhat of an orthodoxy or mainstream on design science in IS at the current time, there are other views emerging (see, for example, Carlsson 2006, 2007; McKay and Marshall 2005, 2007; Niehaves 2007a, 2007b; Niehaves and Becker 2006). These papers question some of the perspectives adopted and promoted by the mainstream and put forward alternative perspectives on design and design science. Given this, the argument that will be articulated and explored in this chapter is that some of these differences could stem from differences in how information systems themselves are conceptualised and in how the construct 'design' is conceptualised. Indeed it will be argued-based on arguments articulated by Campbell (1979) in writing about the concept of organisational effectiveness - that no single, all-encompassing definition of either IS or design in IS can be established. Rather it will be asserted that a particular conceptualisation of design in IS could be useful only in certain circumstances, and thus to be made sense of it must be located within a theoretical framework or context of what IS is perceived to be. This builds on the notions articulated by El Sawy (2003), who noted, in comparing different positions put forward in the 'What is the core of IS?' debate, that any single perspective is just that: a single view among many possible views of 'reality'. El Sawy (2003) notes that each perspective both highlights and backgrounds different elements: different perspectives are not right or wrong, but offer differing views and insights. In applying this thinking to design in IS, we can conclude that the differing positions emerging are helpful to build knowledge about the perspective of design adopted and that multiple perspectives could be useful in building a broader-based design science in IS. Thus, depending on the circumstances, different conceptualisations of design, of IS and of design in IS could be necessary and helpful in building an overarching IS design science. From this perspective, it would be limiting to take too parochial a view in defining such terms, as in doing so we could limit the applicability of our research findings in these important areas. 
This chapter will thus argue for multiple conceptualisations of design to be accepted as applicable within the field of IS, and thus the production of new knowledge of design in IS - the very basis of building a science of design in IScan progress along a much broader front. Further, the chapter will argue that in addition to the important work already undertaken by Hevner et al. (2004), Walls et al. (1992), Markus et al. (2002), and others, in starting to articulate what we here label as a technology-centred design science in IS, knowledge needs also to be built in a human-centred design science (Roth 1999:24) in IS. Together, the technology-centred design science and the human-centred design science will offer greater insights and account for more contexts than either will on their own, and should thus serve to progress the understanding of design in the IS discipline.

The chapter is structured as follows. In the sections that follow, Hevner et al.'s position on design science will be discussed and from that we will deduce and argue that their views on design science stem from a particular view of IS - akin to what El Sawy (2003) describes as a connection view of IS. The chapter will then consider the domains of design and use this to consider the ways in which design is conceptualised in many non-IS disciplines - among them management, organisational development, architecture, engineering, industrial design and education. Such conceptualisation will then be compared with the ways in which design would appear to be conceptualised in the current IS designscience literature, and it will be shown that in IS design science currently, there is a much narrower view of design. If we accept Campbell's (1979) argument, this would suggest that the science of design that is being built will be constrained by the conceptualisations we have of design. The chapter will then discuss a number of issues associated with this conceptualisation and will suggest other ways of thinking about, and hence conducting research into, design and IS. The chapter concludes with an argument that both technology-centred design science and human-centred design science are needed to together advance our understanding of design in IS along a broader front and to thus build an overarching theory of design in IS.

\section{An exploration of Hevner et al.'s position}

Hevner et al. (2004) delineate IS knowledge as falling within two paradigms: the behavioural science and the design-science paradigms. Essentially, they argue that design science in IS is about the design of 'new and innovative artifacts' (Hevner et al. 2004:75) - IT artefacts - which are then implemented or instantiated in particular situations to solve problems identified within organisational contexts. In contrast, it is argued that the behavioural paradigm seeks to explain and predict 'organizational and human phenomena surrounding 
the analysis, design, implementation, management, and the use of information systems' (Hevner et al. 2004:76; emphasis added). In Figure 5.1, from Hevner et al. (2004:79), the relationships between business and IT strategies and infrastructures are depicted, and it is noted that the interplay between these four elements is seen as rightly falling within the interests of IS researchers. While Hevner et al. (2004) recognise that there are many design activities involved in realising alignment between IS and the organisational strategiesthus effectively exploiting the capabilities of IT to enable the organisation (and its members) to achieve its goals and objectives - their interest in design science in IS is, however, limited to the design activities associated with the building of an IS infrastructure (circled in Figure 5.1). Hevner et al. (2004:78) write that '[o]ur subsequent discussion of design science will be limited to the activities of building the IS infrastructure within the business organization. Issues of strategy, alignment, and organizational infrastructure are outside the scope of this paper.' This and subsequent statements in their paper - 'we do not include people or elements of organization in our definition [of the IT artefact], nor do we explicitly include the process by which such artifacts evolve' (Hevner et al. 2004:82) and 'artifacts constructed in design science research are rarely full-grown information systems that are used in practice' (p. 83) - would seem to reveal world views (perspectives) on both 'design' within an information systems context and 'information systems', which serve to delimit their subsequent argumentation.

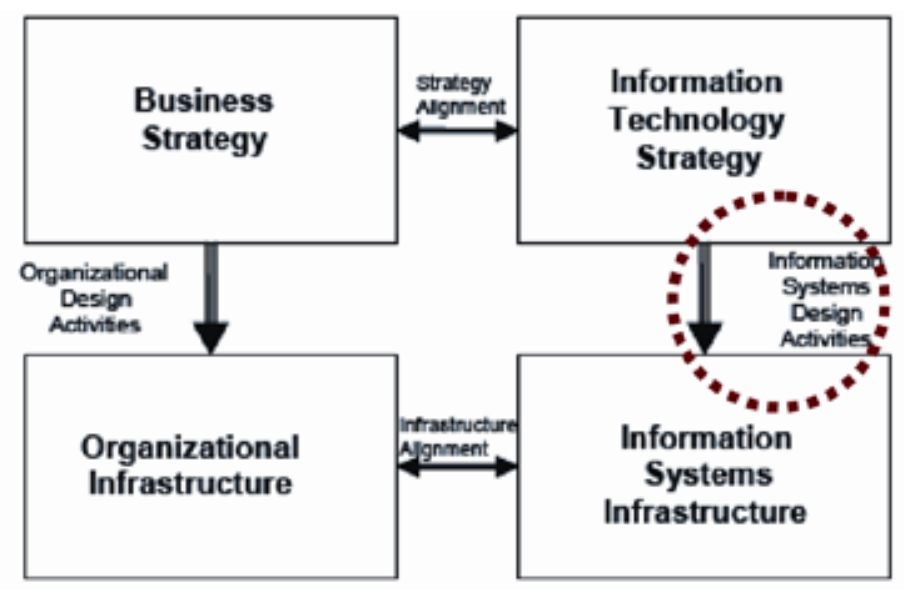

Figure 1. Organizational Design and Information Systems Design Activities (Adapted from J. Henderson and N. Venkatraman, "Strategic Alignment: Leveragin Information Technology for Transforming Organizations," IBM Systems Joumal (32:1), 1993.)

Figure 5.1 The focus of design interest in IS according to Hevner et al. (2004) 
Carlsson (2007) argues that in the writings of Hevner et al. (2004) and other key authors such as Walls et al. (1992), March and Smith (1995) and Cao et al. (2006), design and the design-science paradigm in IS are arguably presented as being about the IT artefact - that is, elements of the innovative combination of hardware and software and the means by which these can be realised (specific instantiations or models, representations, constructs, vocabulary and the like surrounding the technical artefact). Hevner et al. (2004:78) note the dichotomy that design is about product (the artefact itself and attendant methods and models, for example) and the process, the set of activities by which such innovative products are produced. Another important distinction is drawn between what they describe as routine design and design-science research. Routine design is characterised by applying existing knowledge and IT artefacts to organisational problems, whereas design-science research focuses on finding innovative, new solutions to important unsolved organisational problems and, from this, new knowledge can be added to the existing knowledge base around design in IS (Hevner et al. 2004:81). In addition, they argue that other interests - the social, cultural, political and human dimensions associated with the implementation, use, acceptance and exploitation of the technical artefact in an organisational context - all fall within the behavioural-science paradigm in IS. This, then, suggests a particular view of design and IS, which is illustrated in Figure 5.2.

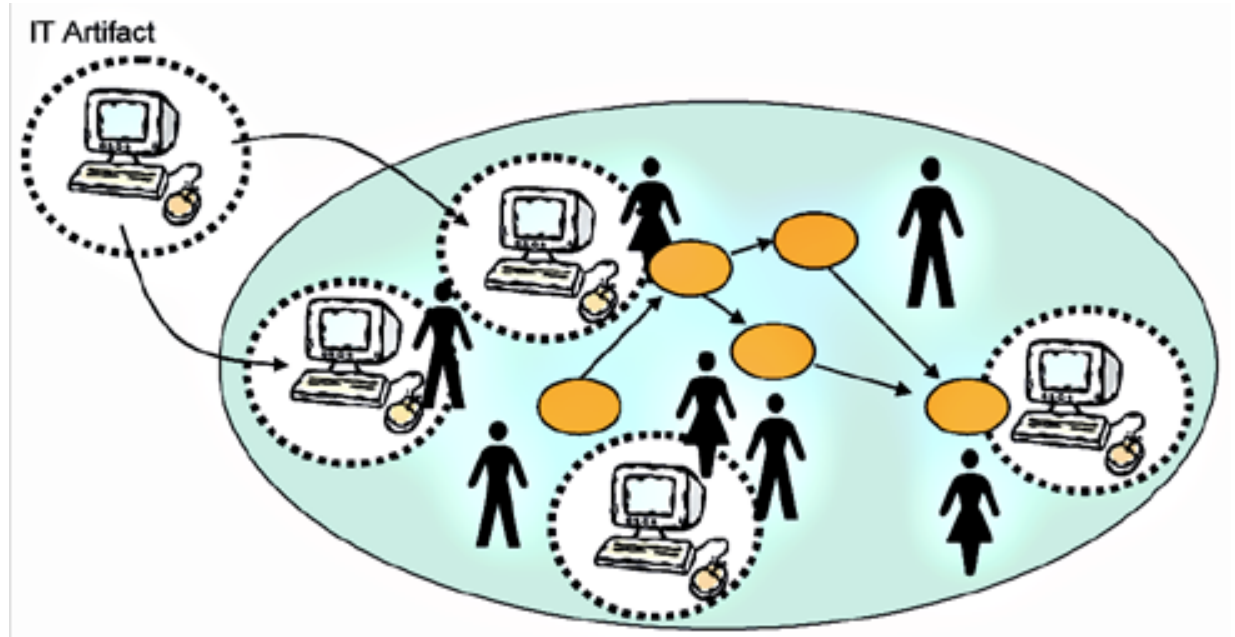

Figure 5.2 The IT artefact 'surrounded' by the organisational context.

The IT artefact in Figure 5.2 is viewed as consisting of the new innovations described by Hevner et al. (2004), which could be combinations of innovative software and hardware (instantiations) or constructs, models and methods, and the like. This IT artefact is of interest to the design-science researcher who, through building and evaluating such artefacts, builds knowledge in the designscience paradigm. The knowledge, insights and skills revealed by a design- 
science researcher collectively build a science of design. For the purposes of this chapter, we will refer to this as a technology-centred design science. The IT artefact can then be implemented into an organisational (socio-technical) context, and hence the 'things' in the organisation can become of interest to the IS researcher working in the behavioural-science paradigm. Note that such artefacts are seen as being 'surrounded' by human and organisational phenomena or arguably as being able to be split out from the organisational context in which they are implemented. Thus, the Hevner et al. (2004) conception of IS would seem to embrace a bounding of the IT artefact from other constituent elements of an organisational context. There would appear to be similarities between this and what El Sawy (2003:591) describes as the connection view of IS, in which IT is 'a separate artifact that can be connected to people's work actions and behaviors'.

Hevner et al. (2004:78) note that other design activities of interest to IS researchers are evident in organisations (labelled 'Organizational design activities' in Figure 5.1), but argue that research into these aspects of design falls within the behavioural-science paradigm. Thus, within IS, knowledge built about design is seen as falling across two paradigms: the design-science paradigm for technology-centred design science and the behavioural-science paradigm. This causes some discomfort; the recognition of the building of a science of design in IS is shared broadly across the IS academic community, but the position adopted by Hevner et al. (2004) would appear to result in a split between two different spheres of design knowledge. It is the authors' contention that such a view is not held in other, non-IS disciplines in which design is of considerable interest. Further, it will be discussed whether the connection view of IS (El Sawy 2003) leads to a narrow conceptualisation of design in IS. The question to be considered is whether a different and broader conceptualisation of design in IS might be helpful in building new and insightful knowledge and practices about design as it impacts on IS.

\section{Design in different contexts and disciplines}

Design is not an activity or phenomenon that is solely the province of IS researchers and practitioners. Indeed, it is a very broad concept and has developed a very substantial literature in a variety of disciplines and fields. In this section, we consider the conceptualisation of design in disciplines other than IS to see if there are insights to be gained from the way others construct, and thus understand and research, design.

Buchanan (1989) argues that design is impacted and shaped by essentially three 'domains of knowledge' (see Figure 5.3): the need to make things work properly (engineering-type knowledge), the need for the form and appearance 
of designed artefacts to meet appropriate aesthetic requirements (knowledge from art and aesthetics) and knowledge of the human sciences, of how people communicate and relate to artefacts within particular contexts.

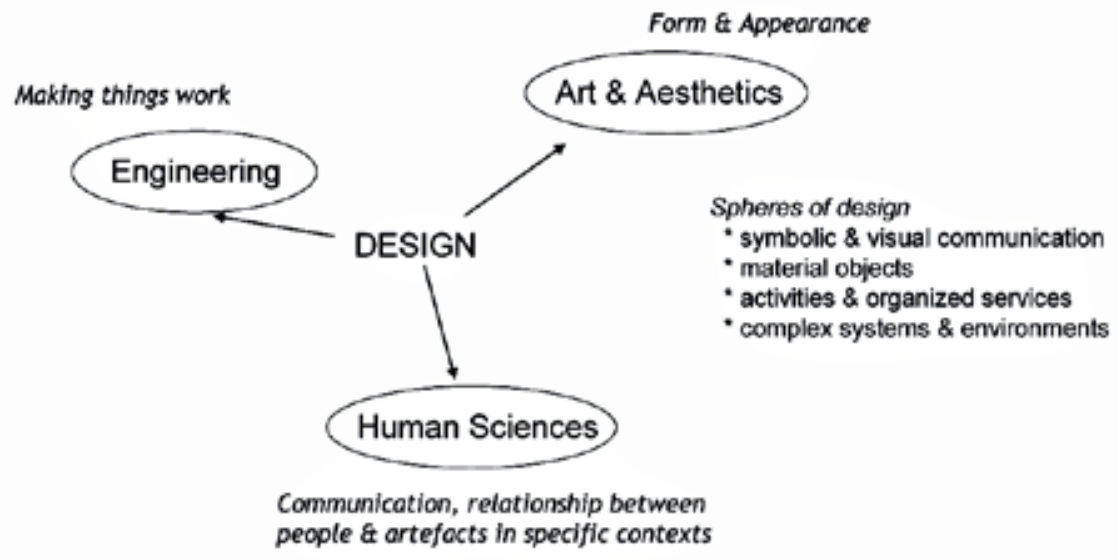

Figure 5.3 The three domains of knowledge impacting on design spheres of activity

Buchanan (1992) argues that there are few aspects of contemporary life that are untouched by design and suggests that there are four broad spheres of design activity, which are not discipline specific, but rather that characterise the application of design ideas to very different problem types and different subject matters. These will be described briefly as they serve a useful starting point for a consideration of how design is conceptualised in different contexts and disciplines. The first of these Buchanan (1992) labels as design of symbolic and visual communication, which includes traditional graphic design and illustration, but now includes film and television, photography and computer display. The second area he describes as the design of material objects, which embraces a wide range of everyday items, including tools, machines, vehicles, apparel and domestic objects. Buchanan (1992:9) notes a trend in the literature to move from thinking purely of the object itself to a broader interest 'and diverse interpretation of the physical, psychological, social and cultural relationships between products and human beings'. The third area is the design of activities and organised services, which embraces the organisation of various resources in efficient sequences and schedules so that particular objectives can be achieved. This area is concerned particularly with logistics and logical decision making, but Buchanan (1992:9-10) also notes a recent shift to a broader consideration of 'how better design thinking can contribute to achieving an organic flow of experience in concrete situations, making such experiences more intelligent, meaningful and satisfying'. The final area is the design of complex systems or 
environments for living, working, playing and learning. This clearly includes town planning and architecture, but Buchanan (1992:10) again notes a shift in emphasis to embrace 'the central idea, thought, or value that expresses the unity of any balanced and functioning whole'. Against this very broad backdrop, it is now possible to consider the ways in which design is conceptualised in a range of non-IS disciplines.

\section{Design as problem solving}

Across many disciplines, design is commonly referred to as problem solving, a way of defining problems (Boland et al. 2008; Buchanan 1992), and it is argued that this rational problem-solving view of design has become dominant and normalised in conceptualising design in many disciplines (Dorst 2006). When viewed as problem solving, design is often characterised as a 'means of ordering the world' (Dilnot 1982:144), of meeting needs and making desired improvements, of transforming and improving the material environment (Friedman 2003; Willem 1990). Emphasis is often placed on design involving careful analysis and definition of the problem and on gathering adequate information about the problem before seeking solutions (Kruger and Cross 2006). In some conceptualisations of design as problem solving, however, the emphasis is placed not so much on the notion of there being a problem, but rather on design as being the solution to the problem. In this way, the conceptualisation of design shifts slightly to generating solutions and, at times, redefining the problem in light of these emerging solutions (Kruger and Cross 2006). It is thus argued that design solves problems by being solution oriented, as involving designing or developing solutions to situations regarded as problematic by stakeholders (Keys 2007; van Aken 2007). These design problems are of certain types, however, with van Aken (2007) distinguishing between knowledge problems (which arise through limitations in knowledge) and field problems (which arise from a recognition or desire to realise a better social reality). Design is seen as solving field problems and the problem-solving activity involves not only designing a solution but also realising or implementing that solution in some material or social reality.

\section{Design as product}

Many writers note the distinction between 'design' as a noun (an object or product) and 'design' as a verb (an action or process). In conceptualising design as a product, writers generally refer to objects, entities or artefacts that arise within particular social and historical contexts and are imbued with meaning within those contexts (Dilnot 1982). This type of definition - in which the focus is clearly on the designed artefact - has been called the 'product view of design' (Marxt and Hacklin 2005:414), and there is often reference to the importance of design's involvement in giving material form to a problem solution, of the 
artefact meeting some perceived need or solving some sort of organisational, technical or human problem (Willem 1990). The concept of design as product thus sometimes is linked into discourse about consumption and the economics of production (Teymur 1996). The role of the designer is often mentioned and always assumed, in the sense that the designer is seen as adding characteristics of desirability and/or utility to the object of interest (Dilnot 1984a), which serves to emphasise that the design of products is an outcome of human creativity and industry. The designer is thus inextricably linked to and involved with the product of design; design is thus not viewed as a mechanistic replicable activity, for whereas replication in the physical sciences is seen as possible and quite independent of the scientist, the designer working within a particular context gives rise to the shape and form of the artefact produced.

\section{Design as process, action}

The limitations of the product view of design arguably stem from the fact that the activity or process involved in materialising a problem solution is marginalised, and thus definitions of the product view of design cause angst in some circles, where there is a tension perceived between the product of creation and the activity of creation. For example, Miller (2004) asserts that the product or result of creation is an entity, an output of design, but is not design itself. Thus, from this perspective, a chair is a chair, an output of designing a chair, but a chair is not itself a design. In contradistinction to the product view of design, there is what could be called the process view of design: design is a process, a series of thoughts and activities by which an artefact is created and realised (Andreasen et al. 2002; Miller 2004). The concept of problem solving is often retained in definitions of these types, in which design is seen as the activity involved in moving from a vague, possibly ill-defined problem to a clear and creative response, and in these activities shaped by context lies the essence of design (Ryan 1997). The goal of design from this perspective is thus to take action and to produce change in human contexts (Willem 1990). Galle (1999) takes this notion a little further and calls for an expansion of the notion of design such that it embraces all human activities dedicated to both realising an artefact and embedding that artefact in a context of use in which it is met with approval and use (or not).

\section{Design as intention}

In some literature, the aspect of design that is emphasised is generally its utility and the fact that it results from intentional activity (Dipert 1995; Hilpinen 1995). Thus, an extension of the notion of design as activity is the view of design as intention or intentional activity. Miller (2004) emphasises the importance of intentional thought processes in design activity, including insight by which a designer is able to see connections between problem (challenge) and possibilities, 
intuition and hunches and reasoned problem solving, which are synthesised throughout the design process. Willem (1990:45) argues that 'design occurs when the intention to design is present', suggesting that it is an intentional creative response to external events. Galle (1999) notes the potential complexity when, from this perspective of design, not only the designer's intentions but those of the problem owners and solution users become enmeshed in the design activity. This view of design puts the focus clearly onto the internal thought processes of the designer and how they can be guided by the intentions of the user of a design, and the context of use.

\section{Design as planning (modelling, representation, method)}

Furthering the view of design as intention, Buchanan (1992:8) argues that design can be regarded as a plan or 'working hypothesis', which constitutes or formalises the designer's intention. Along similar lines, Dilnot (1984b, drawing from the work of Papanek 1974) suggests that design can be thought of as a conscious attempt to plan and build patterns that will then shape the emergence of an artefact from a conceptualisation of the designer. Wieringa and Heerkens (2007) broadly agree with such viewpoints, arguing that design involves specifying what you intend to do before you in fact do it, and thus is fundamentally concerned with conceiving and planning something in one's mind. Galle (1999:65) refers to this as the problem of the 'absent artifact', the challenge of conceptualising, planning and realising something that does not currently exist. Dilnot (1984a) notes that before the Industrial Revolution, designing, planning and making artefacts were conceived of as one construct. Typically, since the onset of the Industrial Revolution, however, the planning and designing of artefacts have been separated from the making of artefacts. The perspective of Galle (1999) is sympathetic to this view, as he argues that in the process of realising an artefact and embedding it in its context of use, there are several stages of planning involved. Thus, in moving from conception of a solution to realised artefact, there are stages of design representation or plans, including conceptual, logical and physical plans and models. Van Aken (2005a) argues that such plans are themselves designs - the plans and sketches of a house, for example, are the design of the house. According to the conceptualisation of van Aken (2005a), following the design is another stage of planning, the plans of action and activities involved in the realisation of the physical artefact, in which the design representations are transformed into an artefact of utility. As in many disciplines, conceiving designs and making artefacts now involves significant complexity and knowledge intensity; another form of design as planning emerges - that of design of the design process itself. In other words, in large, complex projects, the processes involved in design 
representation and the processes involved in realising the design can be of such complexity that these processes could themselves need designing. This van Aken (2004) has called design-process design.

\section{Design as communication}

Buchanan (1989:105) asserts that 'some kind of communication exists in designed objects'. This argument is justified in asserting that designers either knowingly or unknowingly enshrine human values and opinions in their designs, based on their own world view and on their understanding of either a specific or a general audience for which the design is intended. A design resonates with an audience when it appeals to their interests, values and attitudes, for example, and in this way communicates with its audience (Lunenfeld 2003). Kazmierczak (2003) argues that design is the process by which the meanings intended by the designer are communicated to an audience and received either as intended or as reconstructed by the audience given their context, values and the like. Thus, Kazmierczak (2003:45) defines designs as 'cognitive interfaces that enable reconstruction of intended meanings'. This perspective of design is thus quite different from many of those presented above. It moves from notions around objects or artefacts, and the processes by which the artefact is realised, and rather focuses on the conceptual characteristics embodied in objects that serve to communicate with their audience or users. Kazmierczak (2003:45) writes that '[i]t redefines designs from finite, fixed objects of aesthetic and practical consideration to semiotic interfaces enabling the reconstruction of meaning by receivers'. Defined in this way, design becomes associated with form and content, with emphasis placed not just on the role of the designer in shaping form, but also on an essential role of the designer in shaping communicative content that is evidenced through the meaning, interpretations or thoughts a design induces in an audience. Design, thus conceived, becomes linked to a designer using the 'right' language to express his/her intentions in a way that can be accurately comprehended and responded to by the audience (Krippendorff 1996; Redstrom 2006). Kazmierczak (2003:48-9) argues that 'designs are not designs unless there is a receiver' and suggests that the success of a design is dependent on the successful comprehension of the design by its intended audience.

\section{Design as user experience}

The notion of design as communication is extended by Redstrom (2006), who suggests that design is best conceived as the user's experience of an object. Thus, it is not just the communicative element of design that is important, but the experiences that design creates and enables for its recipient audience. In this way, the user or audience becomes the subject of design, through their 'dynamic and multisensory' experiences of an artefact (Redstrom 2006:126). This represents a substantial shift away from the object or artefact and the processes 
surrounding the conceptualisation of the object and its physical realisation. Design thus becomes concerned with how one designs user experiences, not just in terms of utility or usability, but in terms of communication, interpretation, understanding and experience (Boztepe 2007; Kazmierczak 2003; Redstrom 2006).

\section{Design as value}

Some writers note that design itself has become associated with value - often not an intrinsic part of the artefact itself, but as some sort of iconic status that becomes associated with a particular object. In this sense, we get expressions such as 'good design', 'designer jeans' or 'designer labels', in which value becomes associated with the significance attached to an object rather than the object itself (Dilnot 1984a, 1984b). The designer involved in the valueassociation view of design is often conceived as the loner-hero-artist - often an iconic and easily recognisable figure to a certain subculture. Their audience or users value the objects they design by what they communicate or mean to a wider audience, and thus value becomes associated with what the object comes to symbolise (Lundgren 1978).

\section{Design as professional practice}

Many definitions of design include close consideration of the designer and some come to argue that design is 'what designers do' (Dilnot 1984b). Thus, design starts to be conceptualised more as professional practice, with identified responsibilities to clients, fellow designers, the public and broader social and environmental responsibilities (<www.aiga.org $>$ ). Design as a professional practice can be viewed as a way of thinking and an attitude towards a design task (Wangelin 2007), as a practice delimited by the design task (Hooker 2004) or as engagement directly in a specific design activity (Fallman 2003). This view of design emphasises the situatedness of the designer in a real-world context involving uncertainty, ambiguity and value conflict (Fallman 2003, citing Schon 1983), and inevitably links design to the personal experiences, capabilities, knowledge and intuition of the designer. In this way, Louridas (1999) and Wangelin (2007) argue that design is bricolage - an attitude towards a problem in which previous knowledge and experiences, tools and resources can be intuitively adapted and applied to a current challenge. This view of design serves to emphasise the subjective nature of interpretation and value judgments made about the problem at hand, the intended audience, and so on. Considering design as a professional practice implies a need to think much more closely about the knowledge, skills and attributes required of designers as they conceptualise and realise artefacts intended to improve problem situations 
(Friedman 2003; Keys 2007), and hence, a need to retain a 'sense of design as a pluralistic and multiple activity, a synthesis of heterogeneous activities defined not by the separate activities, but by their integration' (Dilnot 1982:141).

\section{Design as service}

When thinking about design, often the vision that tends to emerge is that of a lone designer, a hero figure, who is highly creative, innovative and bold and who manages to turn the design of a product with various aesthetic values into an outlet for personal expression (Dilnot 1984b). Lundgren (1978) shies away from this, arguing that in post-industrial societies, most design activity is centred on service provision rather than heroism or what Dilnot (1984b:4) describes as 'non-esthetically motivated service...or problem solving design'. Lundgren (1978:20) writes that 'design activity...has so much more to do with sustained service, an anonymously methodical day-in, day-out solving of problems, than with the constant ferment of creative choices exercised by the loner hero-artist'. In this view, designers function to effectively solve problems presented to them by others. The design-as-a-service view encapsulates the ability to understand the problem as experienced by these problem owners and their objectives in seeking a resolution of that problem. The context in which the problem is embedded is thus critical to successful design. The designer must, in addition to the skill requirements for designing in a particular field, have insights into and appreciation of the cultural, political and moral aspects of social forces that shape individual perspectives of the problem and that of possible solutions (Keys 2007).

This list of differing conceptualisations of, and nuances associated with, the construct design from non-IS fields is not intended to be exhaustive - nor are these mutually exclusive. There are clearly overlaps and close relationships between the differing perspectives of design discussed here. It illustrates, however, some of the ways in which design is understood, taught and researched in a range of non-IS fields. Willem (1990) notes that it could be 'disconcerting' to take such a broad view of a range of possible activities and entities that are considered under the rubric of design. To not do so, however, is to arbitrarily assign the label of design to a subset of these activities, which Willem (1990) argues could seem somewhat capricious. Willem (1990:45) goes on to note that 'the recognition of a large host of coherent activities as design may provide a richness of experience that is presently missing'. He notes that science accommodates a large range of disciplines and activities within its fold without having a detrimental effect on any of them. Design can do likewise. Further, this broader conceptualisation of design, we argue, helps make sense of a statement made in the introduction - based on the arguments of Campbell (1979) - in which it is argued that no single, all-encompassing definition of design can be established. Rather, any particular definition of design delimits 
a world view of design and thus locates design within a particular frame or context. Knowledge production is then also located within that context and, while it could offer important insights about that particular world view, it is also limited in not offering insights into the many other possible world views that could be entertained.

\section{Design in IS}

Table 5.1 offers a comparison of the ways in which design is conceptualised in non-IS areas as opposed to its conceptualisation in IS journals. To construct Table 5.1, the authors independently read the papers listed, identifying the ways in which design was conceptualised. These independent assessments were then discussed and consolidated. The table is presented here for noting, as indicative of what we believe to be a tendency that is of interest in this chapter.

In disciplines other than IS, we see a very broad understanding of design and this arguably shapes the ways in which researchers consider suitable topics for research within design and how such knowledge can best be produced. When compared with IS publications, the contrast is quite stark. In the small sample of papers examined for illustrative purposes, currently there are four predominant conceptualisations: design as problem solving, design as product or artefact, design as process - often referred to as building and evaluating - and design as planning, modelling and representing (see Table 5.1).

The concepts of design as product and design as process or activity are well represented in the current IS design-science literature (see Table 5.1). Design as problem solving is also represented, but less so. A key reference in this context is Hevner et al. (2004), who mention that the design-science paradigm is a problem-solving paradigm in the sense that information systems are often, or at least should be, designed to solve an identified organisational problem. Other authors, such as Niehaves (2007b), follow Hevner et al. (2004). In Niehaves' (2007b) paper, the notion of problem is broadened to include social constructionist formulations and an increased focus on organisational context. 
5. An exploration of the concept of design in information systems

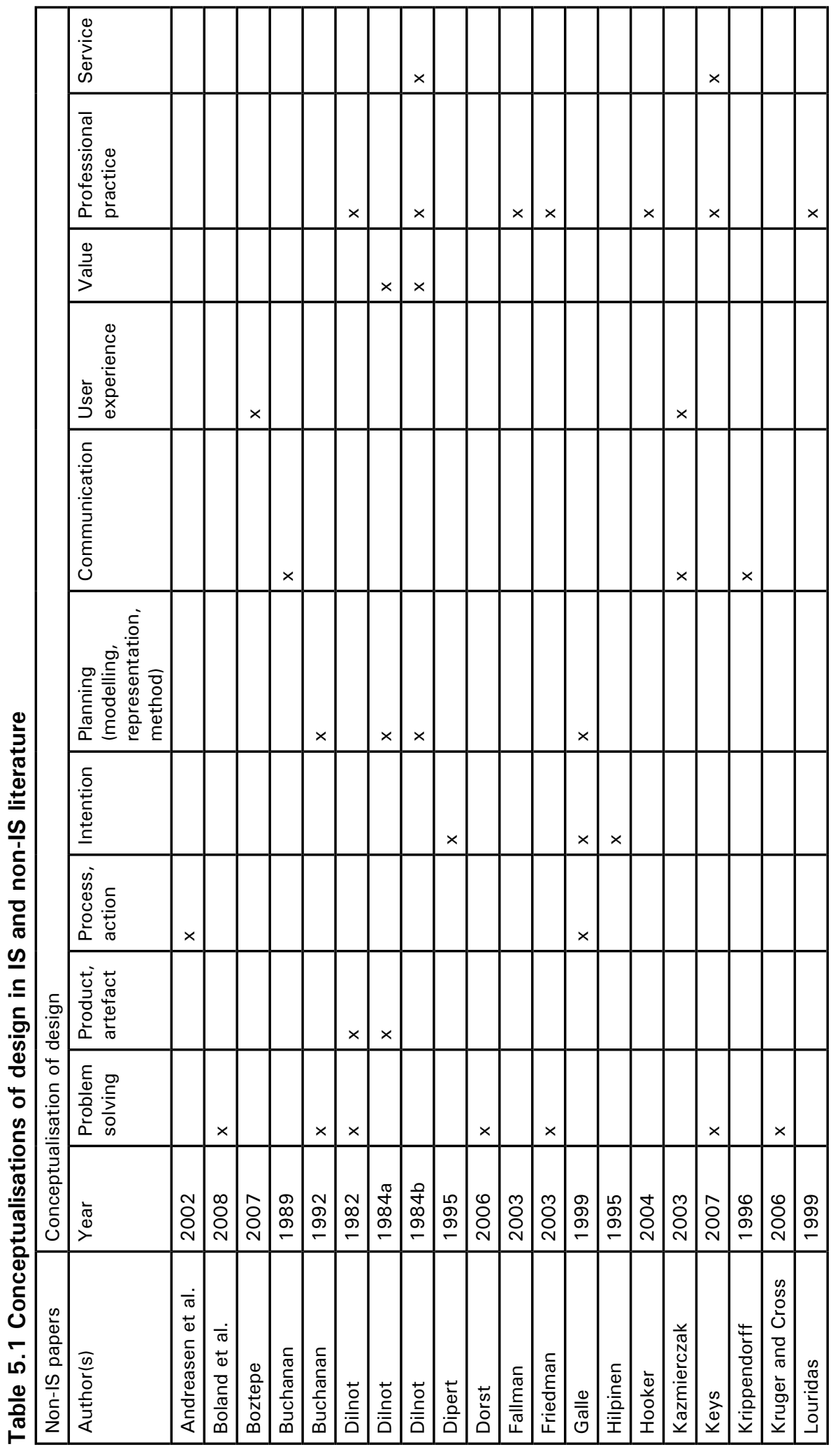


Information Systems Foundations: The Role of Design Science

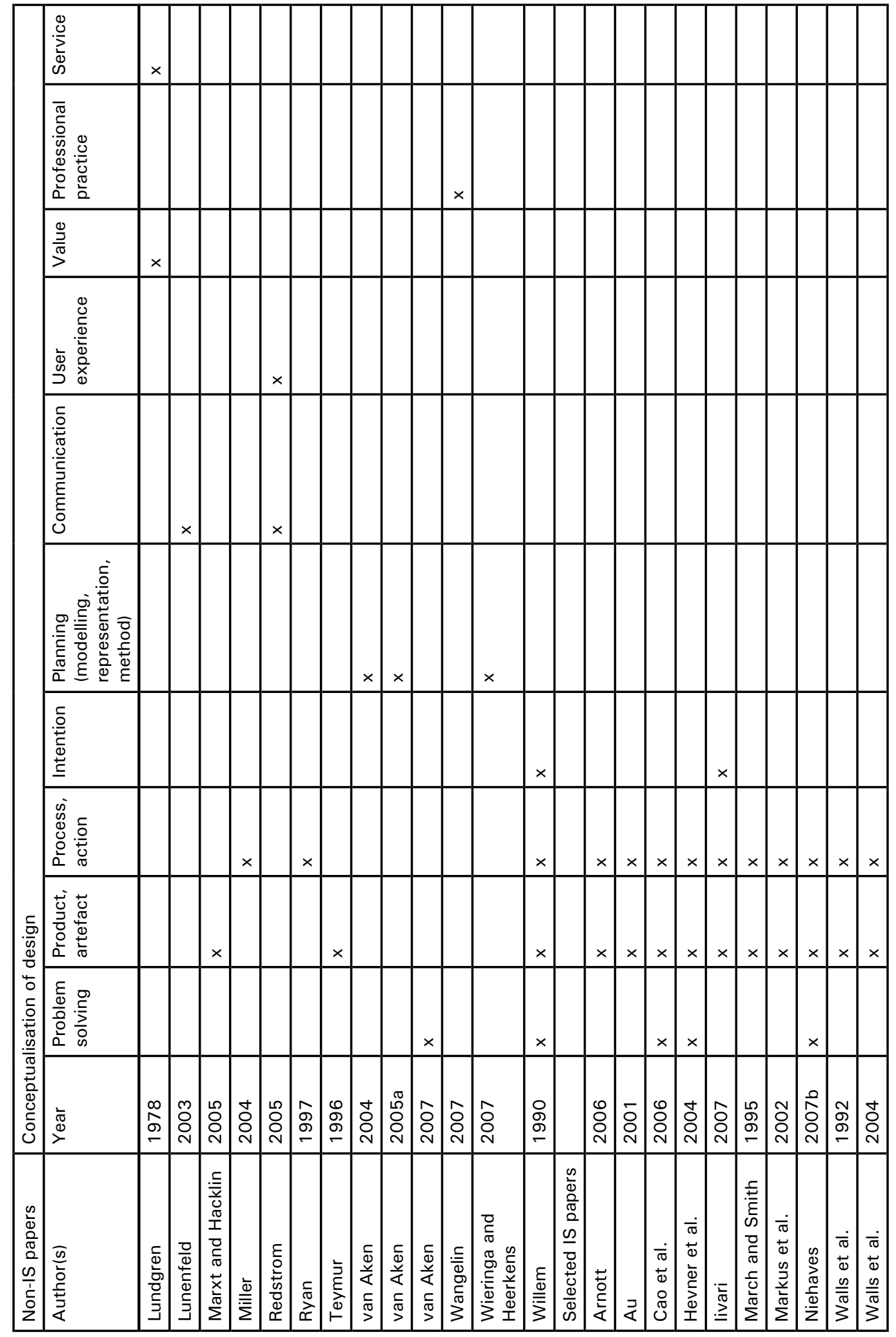


In terms of design as product, the literature clearly discusses the design of software, modelling approaches and innovative combinations of software, hardware and networks, for example. The focus is clearly on the technical artefact, however, and there is seldom consideration of a designed organisational space, context or environment as being a product of design. For example, Hevner et al. (2004) mention distributed database designs that include network latency considerations but would be unlikely to view such artefacts situated in an organisational context with attendant process change, work and information flow changes, job design changes and so on all holistically viewed as a design product. Thinking about and researching such phenomena could add important knowledge to a design science in IS. There is, however, almost no attention paid to the concepts discussed by Teymur (1996) of consumption and the economics of production in IS design science. For example, there is no research into the move from bespoke to packaged software or what this means from a design perspective. Largely absent too in the IS design-science literature is the explicit role of the designer in shaping designs, in embedding values, beliefs and an ethical position within software, in understanding the creativity and creative processes by which thought becomes artefact, and so on. Both Markus et al. (2002) and Arnott (2006) explicitly concern themselves with design as process, and in other IS design-science literature, notions such as approaches to modelling and systems development are featured. There appears to be little research, however, into the processes involved in advancing from fuzzy, illdefined problem to creative response to instantiation or artefact. McKay and Marshall (2007) discuss this process, but do not conduct any empirical research into such processes. While there is undoubtedly IS literature surrounding taking action and producing change when implementing IS in organisations, this is rarely — with the possible exception of Markus et al. (2002) - framed as design. Arguably, there is great opportunity to think of IS implementation in terms of designing organisational contexts and spaces and much that can be learned from considering the design-science literature that has developed in the field of organisational development (see Romme 2003; Trullen and Bartunek 2007; van Aken 2007).

Thinking of design as intention obviously overlaps with both problem solving and process (activity), but note that in the non-IS literature, this conceptualisation involves linking the designer's intention and creativity to action and also to the intentions of problem owners and those of solution users. These all seem fertile ground for design-science research in IS, but are notably absent from much of the current IS design-science literature. Design as modelling, representation and method or planning has historically been well represented in the IS literature and is also featured in the more recent IS designscience literature. There seems, however, to be scope to research the impacts of models and methods - for example, on the creativity and intentions of the 
designer, the problem owner and the solution user-on how these models and methods contribute to shaping solutions. Further, there is little discussion in IS design science of Galle's (1999) idea of the absent artefact, the intrigue that surrounds how one effectively models, plans and represents something that does not yet have material form, but that could have conceptual 'realness' for stakeholders in the IS artefact.

Whereas in other disciplines areas of research have emerged on product semantics (Krippendorff 1996) and the semiotics of interfaces (Kazmierczak 2003), it seems that this whole area of design as communication is absent from current IS design-science literature, although it could feature in some of the HCI literature (Fallman 2003) and the earlier studies in IS (see, for example, Galliers 1987; Stamper 1973). Research into how and why IS designs resonate and communicate with their intended audiences (Lunenfeld 2003) in both intended and unintended ways seems under-done in IS design science - as is a range of topics associated with the ways in which the communicative properties of IS artefacts influence user adoption and appropriation (or lack thereof) of such systems. Design as user experience brings the concept of design in context to the fore, which challenges some of the conceptualisations of Hevner et al. (2004) and others. Thus, users in context as the subject of IS design and how to design IS user experience can become potentially important topics of concern to a holistic, broadly focused and organisationally aware IS design science. The notion of design as value is connected to notions of the semantics and symbol, which likewise seem absent from current IS design-science research. Arguably, many people can associate symbols and values associated with SAP or IBM, for example, but researching these from a design perspective and understanding the impacts and influence ascribing such values to IT artefacts seem not to have been well articulated in IS design science. Thinking of design as professional practice and service poses interesting questions about how IS practitioners really work, how they design and shape organisational spaces and contexts and how as designers they influence the success or failure of IT artefacts, which also seem fertile, but underdeveloped areas for research.

While a much narrower conceptualisation of design in IS design science than that which has emerged in many other design-oriented disciplines might not be of concern per se, the perspective adopted here is that currently IS is far too limited in what is legitimised as a researchable conception of design, thus also limiting what might fall under the rubric of design research and hence what might constitute design knowledge or a science of design. Some of these perspectives discussed above could have been present in IS literature (often dating back 20-30 years - see, for example, the collection of readings in Galliers 1987) but have been underrepresented in the recent swell of interest in design in IS, and opportunity exists to revisit these from an IS design perspective. The 
problem, we assert, is that the current conceptualisation of design in IS design science is too limited to embrace the rich possibilities discussed above. It is our view that the narrow conceptualisation raises a number of important issues, and these will be explored more fully in the next section.

\section{Issues in current conceptualisations of design science in IS}

Thinking about the notion of design in IS requires us to be mindful of the reasons why we design. There are obviously economic imperatives - for greater efficiency and remaining competitive in a global marketplace that is complex, uncertain and turbulent. A design imperative in IS must surely be to help organisations manage these forces and to achieve sustainability in such environments. There are also cultural, social and ethical imperatives that would revolve around thinking about designing information systems that utilise IT to help humans enrich their experience of organisation, of work, of society and of education, to add meaning and value to what they do (Buchanan 1996:79). If we accept both these, it could be argued that we need to build a design science in IS that - in addition to the technology-centred design knowledge-builds knowledge in our designers (and hence creates knowledge, capabilities and a culture among our IS professionals) so that they know how to achieve both these things (economic and socio-cultural imperatives) through their range of design activities in organisations. What they know will limit and shape what they can do-thus, a technology-centred conceptualisation of design will potentially perpetuate technology-centred solutions being proffered as solutions to design problems.

The world view that would apparently underpin Hevner et al.'s conceptualisation of IS (see Figure 5.2 and related discussion) is well suited to the articulation of design knowledge relating to the IT artefact as they define it. It is not, however, sufficient to support the breadth of research activity that could take place under the rubric of design within an IS context if some of the conceptualisations of design from non-IS disciplines were adopted within IS. Opponents of this stance could assert that in the Hevner et al. (2004) view, many of the broader conceptualisations of design and the associated research problems would certainly remain within the interests of IS research, but would be seen as belonging to the behavioural-science paradigm. That is certainly one way of dealing with this problem. We know of no other discipline, however, in which such a separation has been made. In the other disciplines that were included in our reading of the design literature, there had been no such attempt to split design interest and the knowledge that accrued from research into such 
interests into design science and behavioural science. Thus, in engineering (Marxt and Hacklin 2005), in management (Boland 2004; Boland et al. 2008; Friedman 2003), in organisational development (van Aken 2004, 2005a, 2005b), in industrial design (Cross 2001), in education (Brown 1992; Edelson 2002) and in the arts and humanities (Lunenfeld 2003), for example, design and design knowledge are not viewed as being split across two paradigms, but multiple conceptualisations are embraced within a design science. Thus, other world views are possible and important and need to be considered in gaining a new perspective of what the construct design might mean in IS. Figure 5.4 depicts one other possibility.

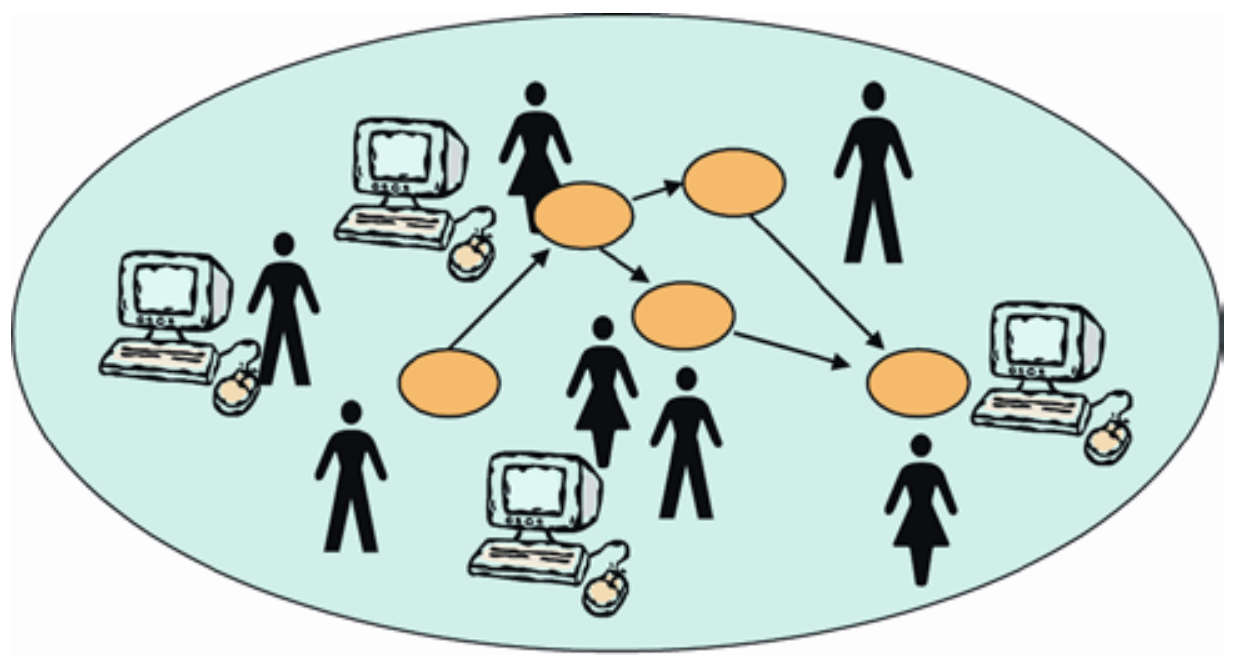

Figure 5.4 A socio-technical view of IS situated in context

The world view captured in Figure 5.4 takes a socio-technical view of IS and thus views IS as fundamentally different from the IT artefact in the 'situatedness' of the technology within an organisational context. An IS emerges from the relationships and behaviours that results in organisational contexts that involve people, activities, information, technology, culture, politics, history and the like. It is not divisible. Viewed in this way, IS is not surrounded by organisational and human phenomena but is part of those phenomena, is socially constructed by designers (IS practitioners) and society shaping (Hughes 1987) and hence shapes and is shaped by the context of use. IT artefacts are components of IS, as are people, activities and so on. But the IS artefact emerges from the interactions and interdependencies that result from looking at the whole, rather than constituent elements. This view seems more in harmony with the fusion view defined by El Sawy (2003). Design in IS in this fusion view occurs in shaping organisational contexts by changing the way information is communicated, stored, created, shared, used, and so on, in shaping the way work is done, in shaping the way 
people interact, in shaping the way organisations are structured and in shaping the way in which cultural and power relationships are played out (Boland et al. 2008). Such design activity must be cognisant of the culture, politics, sociology and history of that context. Thus, the IS artefact and its situated utilisation in a particular wider socio-technical context become the objects of research interest. Indeed, this argument parallels that of Simon (1996) with regard to organisations and management: managers, in creating structures, writing plans, developing processes, policies and procedures and the like, are designingthey are creating organisations or organisational environments as designed artefacts (Boland et al. 2008). We can describe the task of management, then, as responsibly construing and shaping problem spaces and designing artefacts in response to that problem construction (Boland 2004). These designed artefacts, when implemented in the target organisation, form part of the improvement of the problem space or situation. For IS researchers and practitioners, this emphasises the need for broad conceptualisation and interest in design and the need also to recognise, understand and elucidate practices with respect to transforming situations (by the responsible application of IT artefacts) into more desired states, taking account of context and the uses for which people could appropriate such systems. For the purposes of further discussion, we will call this the human-centred view of design. Human-centred design knowledge and technology-centred design knowledge should both be recognised as falling legitimately within a design science in IS.

Hevner et al. (2004) differentiate between routine and innovative design. Innovative design - the fundamental breakthroughs that build knowledge that previously did not exist - is seen as being in the province of technologycentred design science, whereas routine design, applying knowledge of design in organisational contexts, falls outside the bounds of design science and thus presumably within behavioural science. Other authors, however, offer different insights in this regard. For example, Hughes (1987) also draws a distinction between conservative and radical design, which closely parallels the sorts of distinctions made by Hevner et al. (2004). Hughes (1987), however, regards both as design - as would be the case in the human-centred design world view. Willem (1990:45) takes the distinction slightly further in suggesting that design occurs when the intention to design is present and when the action taken is derived at least in part from a creative sense rather than instinct or imitation'. Thus, routine (conservative) and innovative (radical) design are both forms of design - possibly in different contexts - and knowledge accumulated about both should legitimately fall within a science of design; instinctive responses, and imitation, such as mass production are not design. Thus, once again, it is argued that the concept of design has to be made sense of within a world view of design and then it is useful only for a certain purpose shaped by the context. Distinctions between routine and innovative design are highly contingent on world view, and within the human-centred view of design, research into both is essential to build our disciplinary knowledge of design. 


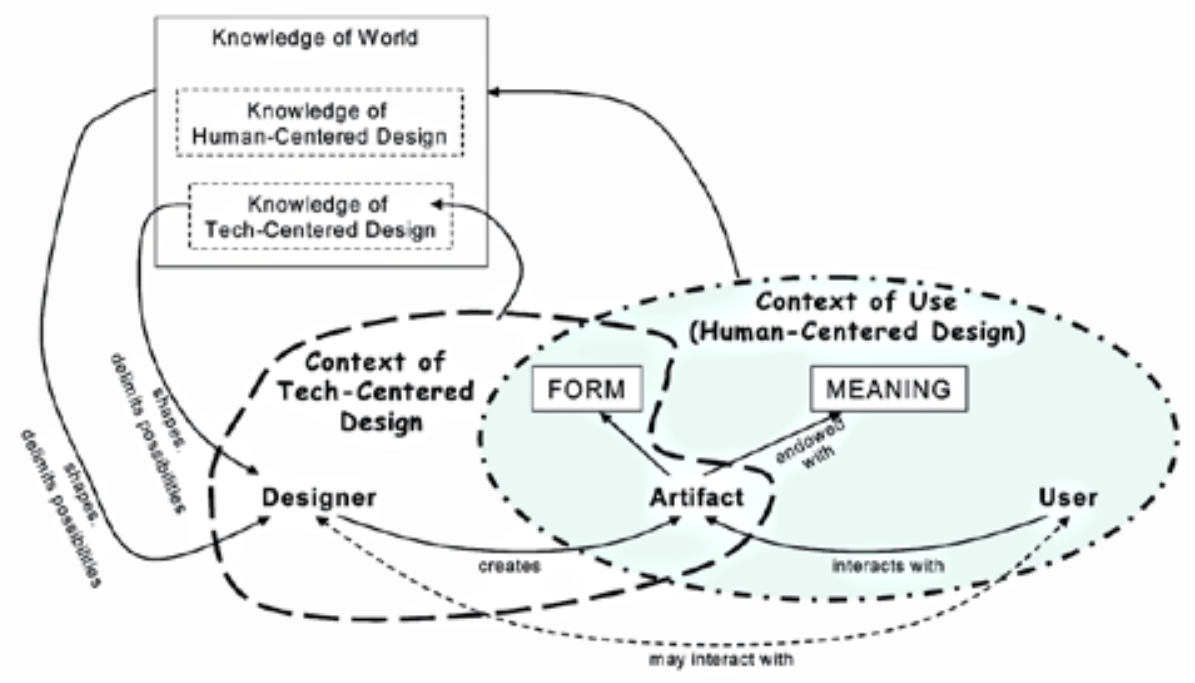

Figure 5.5 Components of IS design science

From Galle (1999); Krippendorff (1996).

From considering the differences between world views, a much more complex view of design starts to emerge (see Figure 5.5). Taking the technology-centred view of design, the focus is on the IT artefact (Carlsson 2007) — specific instantiations or models, representations, constructs, vocabulary and the like surrounding the technical artefact - and the resultant form that it is given as a result of design activity within a context of design. Through research and reflection, the body of knowledge about technology-centred design is built and accumulates over time. When that artefact is implemented within an organisational context, a user interacts with that artefact and endows it with meaning within that particular context of use. Through research and reflection, knowledge of design within organisational contexts (human-centred design knowledge) is likewise built and accumulates over time. Such knowledge bases form part of our knowledge of the world. Designers are inevitably shaped and limited by their knowledge of design in both senses (technology centred and human centred). The world view of Hevner et al. (2004) focuses primarily on technology-centred design and building a design science based on the knowledge accrued in this context of interest; the alternative world view articulated in this chapter focuses primarily on human-centred design and argues that a design science can be built from knowledge accumulated in the context of use. The various perspectives of design can also be interpreted against this diagram and an argument will be put forward to suggest that broadening our current conceptualisation of design can lead to a much richer and broader understanding of design in IS, and hence of the types of research into design that can, and indeed should, be pursued. It 
is also the contention of this chapter that IS as a discipline is better served and greater coherence in the discipline is achieved if these potentially two design sciences are seen as one. If this is to be accomplished, a way must be found to avoid splitting out these interests into design science and behavioural science.

\section{Implications and discussion}

A way forward in the design science-behavioural science dichotomy could be offered by van Aken (2004, 2005a, 2005b, 2007), who suggests that a distinction can be drawn between the explanatory sciences and the design sciences. From van Aken's perspective, explanatory science (physics, chemistry, biology and sociology) attempts to build valid knowledge about the world (both natural and social). It attempts to describe, explain and sometimes to predict natural and social phenomena-hence is concerned with explanation and 'truth'. The outcomes of explanatory research can be a causal model as in the physical sciences, for example, or in the social sciences - an understanding of causal patterns shared between the researcher and an informed audience (van Aken 2005b, citing Peirce 1960). In contrast, van Aken (2007:68-70) suggests that design sciences (such as engineering, medicine and law) are geared towards improving the human condition through finding solutions to 'field problems' problems involving how we design and realise a better reality. Thus, design is seen as solution oriented, involving the design of a solution and the realisation and implementation of a solution in 'material or social reality'. Design science is thus geared more towards making improvements and ensuring that change works well. It is aimed at intervening in contexts to make improvements and is thus oriented towards the future - not just describing and understanding what is. Design science aims to develop knowledge that can be used by practitioners in their field to design solutions to problems. It also aims to develop knowledge of how to implement and particularise the solution in the relevant context (Carlsson 2007; Trullen and Bartunek 2007; van Aken 2007).

Research in design science is thus interventionist and solution oriented, in which the ultimate aim is to produce theories and actionable knowledge (Argyris 1996) that can be used for designing solutions to real-world problems and their implementation and integration in such contexts. Carlsson (2007) echoes similar sentiments to van Aken $(2004,2005$ b, 2007) in suggesting that the outcomes of design-science research would take the form of technological rules, algorithmic or heuristic design exemplars for knowledgeable professionals (practitioners), which would enable them to apply the general knowledge gained from their discipline to specific solutions for specific problem contexts. Whereas in technology-centred design science, algorithmic technological rules might be one outcome, it is anticipated that in human-centred design science, heuristic technological rules - often qualitative in nature - might be the norm. Such 
heuristic rules would mean that practitioners do not start from a blank slate for each designed organisational intervention, but rather they recognise the right solution concept and then design a specific variant that suits a particular context (Carlsson 2007; van Aken 2007). Thus, Hevner's routine design (which was not regarded as design science) would be encapsulated in human-centred design science and if subject to rigorous sound research could result in heuristic technological rules.

Taking a broader view of what design science in IS could be also requires thinking more broadly about the types of knowledge that might form such a science of design. From Keys (2007) and Carlsson (2007), it would be argued that IS design knowledge could include the following in addition to the types of knowledge described by Hevner et al. (2004) and other researchers in the technology-centred design-science area

- meta-knowledge about context (organisational, social, political, historical and cultural setting of the problem of interest)

- tacit and explicit knowledge gained from design experiences in previous projects (problem-solving activities)

- knowledge of how to apply heuristic technological rules and design exemplars, and of how to particularise a heuristic technological rule or design exemplar to suit a specific context

- contingent knowledge of a specific situation (able to recognise the complexity and uncertainty)

- relational knowledge - knowledge of interpersonal relationships, the ability to 'see' what social interactions mean in a particular context

- knowledge of methods, tools and techniques.

The standpoint of the authors of this chapter is that a design science that incorporates the human-centred perspective - and hence expands its perspective and vision to include the types of knowledge above - would be richer and more generally applicable than one that is restricted to the technology-centred perspective of the mainstream or dominant view in the extant IS literature.

\section{Conclusion}

This chapter has assessed the design literature in fields outside IS, such as management, engineering, architecture, organisation development, education and the like, and has concluded that a broad, holistic view of design-and hence of design science - is emerging in these fields. This is leading to a richer and more broadly applicable design science in those fields. We have argued that 
the IS field would also benefit from broadening its current technical perspective of design and design science. Indeed, the importance of a broad viewpoint incorporating considerations of-and emphasising the significance ofpsychological, social and organisational factors has been present in much of the IS research of the past 20 years, but these insights seem to have been forgotten in the recent surge of interest in design and design science in IS. Further, it is not sufficient to characterise the psychological, social and organisational factors as somehow belonging to a different discipline or 'paradigm', as has been done in some of the mainstream IS design and design-science literature. Such an approach leads to a disconnect between the technical and human factors in IS, when all the experience of previous research is that a holistic, integrated view of the human and technical factors is much preferred for generating relevant and practical advice for practitioners and other consumers of research outputs. Thus, it is argued that a holistic and integrated stream of design-science research needs to emerge in IS, embracing both the technology-centred and the humancentred design-research activities and knowledge.

\section{References}

Andreasen, M. M., Wognum, N. and McAloone, T. 2002, 'Design typology and design organisation', in D. Marjanovic (ed.), Design 2002. Volume 1, The Design Society, Dubrovnik, pp. 1-6.

Argyris, C. 1996, Actionable knowledge: design causality in the service of consequential theory', Journal of Applied Behavioral Science, vol. 32, pp. 390-406.

Arnott, D. 2006, 'Cognitive biases and decision support systems development: a design science approach', Information Systems Journal, vol. 16, pp. 55-78.

Au, Y. A. 2001, 'Design science I: the role of design science in electronic commerce research', Communications of the Association for Information Systems, vol. 7, no. 1 (July).

Boland, D. 2004, 'Design in the punctuation of management action', in R. J. Boland and F. Collopy (eds), Managing as Designing, Stanford Business Books, Calif.

Boland, R. J., Collopy, F., Lyytinen, K. and Yoo, Y. 2008, 'Managing as designing: lessons for organizational leaders from the design practice of Frank O. Gehry', Design Issues, vol. 24, no. 1, pp. 10-25.

Boztepe, S. 2007, 'User value: competing theories and models', International Journal of Design, vol. 1, no. 2, pp. 55-63. 
Brown, A. L. 1992, 'Design experiments: theoretical and methodological challenges in creating complex interventions in classroom settings', Journal of the Learning Sciences, vol. 2, pp. 141-78.

Buchanan, R. 1989, 'Declaration by design: rhetoric, argument and demonstration in design practice', in V. Margolin (ed.), Design Discourse, University of Chicago Press, Ill.

Buchanan, R. 1992, 'Wicked problems in design thinking', Design Issues, vol. 8, no. 2, pp. 5-21.

Buchanan, R. 1996, 'Myth and maturity: towards a new order in the decade of design', in V. Margolin and R. Buchanan (eds), The Idea of Design, MIT Press, Cambridge, Mass.

Campbell, J. P. 1979, 'On the nature of organizational effectiveness', in P. S. Goodman, J. M. Pennings and Associates (eds), New Perspectives in Organizational Effectiveness, Jossey-Bass, San Francisco.

Cao, J., Crews, J. M., Lin, M., Deokar, A., Burgoon, J. K. and Nunamaker, J. F. Jr. 2006, 'Interactions between system evaluation and theory testing: a demonstration of the power of a multifaceted approach to information systems research', Journal of Management Information Systems, vol. 22, no. 4, pp. 207-35.

Carlsson, S. A. 2006, Design science in information systems: a critical realist perspective, Seventeenth Australasian Conference on Information Systems, Adelaide, 6-8 December 2006.

Carlsson, S. A. 2007, 'Developing knowledge through IS design science research: for whom, what type of knowledge and how', Scandinavian Journal of Information Systems, vol. 19, no. 2, pp. 75-86.

Cross, N. 2001, 'Designerly ways of knowing: design discipline versus design science', Design Issues, vol. 17, pp. 49-55.

Dilnot, C. 1982, 'Design as a socially significant activity: an introduction', Design Studies, vol. 3, no. 3, pp. 139-46.

Dilnot, C. 1984a, 'The state of design history, part I: mapping the field', Design Issues, vol. 1, no. 1, pp. 4-23.

Dilnot, C. 1984b, 'The state of design history, part II: problems and possibilities', Design Issues, vol. 1, no. 2, pp. 3-20.

Dipert, R. R. 1995, 'Some issues in the theory of artifacts: defining "artifact" and related notions', The Monist, vol. 78, no. 2, pp. 119-35. 
Dorst, K. 2006, 'Design problems and design paradoxes', Design Issues, vol. 22, pp. $4-17$.

Edelson, D. C. 2002, 'Design research: what we learn when we engage in design', Journal of the Learning Sciences, vol. 11, pp. 105-21.

El Sawy, O. A. 2003, 'The IS core-IX: the 3 faces of IS identity: connection, immersion and fusion', Communications of the Association of Information Systems, vol. 12, pp. 588-98.

Fallman, D. 2003, 'Design-oriented human-computer interaction', CHI Letters, vol. 5, no. 1, pp. 225-32.

Friedman, K. 2003, 'Theory construction in design research: criteria, approaches and methods', Design Studies, vol. 24, pp. 507-22.

Galle, P. 1999, 'Design as intentional analysis: a conceptual analysis', Design Studies, vol. 20, pp. 57-81.

Galliers, R. 1987, Information Analysis: Selected readings, Addison-Wesley, Sydney.

Hevner, A. R., March, S. T., Park, J. and Ram, S. 2004, 'Design science in information systems research', MIS Quarterly, vol. 28, no. 1, pp. 75-105.

Hilpinen, R. 1995, 'Belief systems as artifacts', The Monist, vol. 78, pp. 136-55.

Hooker, J. N. 2004, 'Is design theory possible?', Journal of Information Technology Theory and Application, vol. 6, pp. 63-72.

Hughes, T. P. 1987, 'The evolution of large technological systems', in W. E. Bijker, T. P. Hughes and T. F. Pinch (eds), The Social Constructions of Technological Systems: New directions in the sociology and history of technology, MIT Press, Cambridge, Mass., and London, UK.

Iivari, J. 2007, 'A paradigmatic analysis of information systems as a design science', Scandinavian Journal of Information Systems, vol. 19, no. 2, pp. 39-64.

Jenkins, M. A. 1985, 'Research methodologies and MIS research', in E. Mumford, R. Hirschheim, G. Fitzgerald and T. WoodHarper (eds), Research Methodologies in Information Systems, Elsevier Science Publishers, Amsterdam, pp. 103-17.

Kazmierczak, E. 2003, 'Design as meaning making: from making things to the design of thinking', Design Issues, vol. 19, no. 2, pp. 45-59.

Keys, P. 2007, 'Developing a design science for the use of problem structuring methods', Systems Practice and Action Research, vol. 20, pp. 333-49. 
Krippendorff, K. 1996, 'On the essential contests of artifacts or on the proposition that "design is making sense (of things)"”, in V. Margolin and R. Buchanan (eds), The Idea of Design, MIT Press, Cambridge, Mass.

Kruger, C. and Cross, N. 2006, 'Solution driven versus problem driven design: strategies and outcomes', Design Studies, vol. 27, pp. 527-48.

Louridas, P. 1999, 'Design as bricolage: anthropology meets design thinking', Design Studies, vol. 20, pp. 517-35.

Lundgren, N. 1978, 'Transportation and personal mobility', Leisure in the Twentieth Century, Design Council, London, pp. 20-3.

Lunenfeld, P. 2003, 'The design cluster', in B. Laurel (ed.), Design Research: Methods and perspectives, MIT Press, Cambridge, Mass.

McKay, J. and Marshall, P. 2005, 'A review of design science in information systems', in B. Campbell, J. Underwood and D. Bunker (eds), Socialising IT: Thinking about the people. Proceedings of the Australasian Conference on Information Systems (ACIS 2005), Sydney, pp. 1-11.

McKay, J. and Marshall, P. 2007, 'Science, design, and design science: seeking clarity to move design science research forward in information systems', in M. Toleman, A. Cater-Steel and D. Roberts (eds), ACIS2007 Proceedings of the Eighteenth Australasian Conference on Information Systems, Toowoomba, Qld, pp. 604-14.

March, S. T. and Smith, G. 1995, 'Design and natural science research on information technology', Decision Support Systems, vol. 15, no. 4 (December), pp. $251-66$.

Markus, M. L., Majchrzak, A. and Gasser, L. 2002, 'A design theory for systems that support emergent knowledge processes', MIS Quarterly, vol. 26, no. 3 (September), pp. 179-212.

Marxt, C. and Hacklin, F. 2005, 'Design, product development, innovation: all the same in the end? A short discussion on terminology', Journal of Engineering Design, vol. 16, no. 4 (August), pp. 413-21.

Mason, R. O. and Mitroff, I. I. 1973, 'A program for research on management information systems', Management Science, vol. 19, no. 5, pp. 475-87.

Miller, W. R. 2004, Definition of design, viewed 9 June 2007, <http://static. userland.com/rack4/gems/wrmdesign/DefinitionOfDesignl.doc $>$

Niehaves, B. 2007a, 'On epistemological pluralism in design science', Scandinavian Journal of Information Systems, vol. 19, no. 2, pp. 99-110. 
Niehaves, B. 2007b, On epistemological diversity in design science-new vistas for a design-oriented IS research?, Twenty-Eighth International Conference on Information Systems, Montreal.

Niehaves, B. and Becker, J. 2006, 'Epistemological perspectives on design science in IS research', Proceedings of the Twelfth Americas Conference on Information Systems, Acapulco, Mexico, 4-6 August 2006.

Redstrom, J. 2006, 'Towards user design? On the shift from object to user as the subject of design', Design Studies, vol. 27, pp. 123-39.

Romme, A. G. L. 2003, 'Making a difference: organization as design', Organization Science, vol. 14, no. 5 (September-October), pp. 558-73.

Roth, S. 1999, 'The state of design research', Design Issues, vol. 15, pp. 18-26.

Ryan, D. 1997, 'Enzo Mari and the process of design', Design Issues, vol. 13, no. 3, pp. 29-36.

Simon, H. 1996, The Sciences of the Artificial, Third edition, MIT Press, Cambridge, Mass.

Stamper, R. 1973, Information in Business and Administrative Systems, B. T. Batsford, London.

Teymur, N. 1996, 'The materiality of design', The Block Reader in Visual Culture, Routledge, London.

Trullen, J. and Bartunek, J. M. 2007, 'What a design approach offers to organization development', Journal of Applied Behavioral Science, vol. 43, pp. 23-40.

van Aken, J. E. 2004, 'Management research based on the paradigm of the design sciences: the quest for field-tested and grounded technological rules', Journal of Management Studies, vol. 41, no. 5 (March), Blackwell Publishing, Oxford, pp. 219-46.

van Aken, J. E. 2005a, 'Valid knowledge for the professional design of large and complex processes', Design Studies, vol. 26, pp. 379-404.

van Aken, J. E. 2005b, 'Management research as design science: articulating the research products of mode 2 knowledge production in management', British Journal of Management, vol. 16, pp. 19-36.

van Aken, J. E. 2007, 'Design science and organization development interventions: aligning business and humanistic values', Journal of Applied Behavioral Science, vol. 43, pp. 67-88. 
Walls, J. G., Widmeyer, G. R. and El Sawy, O. A. 1992, 'Building an information system design theory for vigilant EIS', Information Systems Research, vol. 3, no. 1 (March), pp. 36-59.

Walls, J. G., Widmeyer, G. R. and El Sawy, O. A. 2004, 'Assessing information system design theory in perspective: how useful was our 1992 initial rendition?', Journal of Information Technology Theory and Application, vol. 6, no. 2, pp. 43-58.

Wangelin, E. 2007, Matching bricolage and hermeneutics: a theoretical patchwork in progress, Design Semiotics in Use, SeFun International Seminar, Helsinki, Finland, 6-8 June 2007.

Wieringa, R. and Heerkens, H. 2007, 'Designing requirements engineering research', Proceedings of the Comparative Evaluation in Requirements Engineering Conference (CERE 07), New Delhi.

Willem, R. A. 1990, 'Design and science', Design Studies, vol. 11, no. 1, pp. 43-7. 